\title{
Association of serum free thyroxine and glucose homeostasis: Korea National Health and Nutrition Examination Survey
}

\author{
Jeonghoon $\mathrm{Ha}^{1}$, Jeongmin Lee ${ }^{2}$, Dong-Jun Lim ${ }^{1}$, Jung-Min Lee ${ }^{2}$, Sang-Ah Chang ${ }^{2}$, Moo-Il Kang ${ }^{1}$, and \\ Min-Hee Kim ${ }^{2}$
}

\begin{abstract}
${ }^{1}$ Division of Endocrinology and Metabolism, Department of Internal Medicine, Seoul St. Mary's Hospital, College of Medicine, The Catholic University of Korea, Seoul; ${ }^{2}$ Division of Endocrinology and Metabolism, Department of Internal Medicine, Eunpyeong St. Mary's Hospital, College of Medicine, The Catholic University of Korea, Seoul, Korea
\end{abstract}

Received: May 13, 2019

Revised : August 21, 2019

Accepted: September 7, 2019

\section{Correspondence to}

Min-Hee Kim, M.D.

Division of Endocrinology and Metabolism, Department of Internal Medicine, Eunpyeong St. Mary's Hospital, College of Medicine, The Catholic University of Korea, 1021 Tongil-ro, Eunpyeong-gu, Seoul 03312, Korea

Tel: +82-2-961-4537

Fax: +82-2-968-7250

E-mail: benedict@catholic.ac.kr https://orcid.org/0000-00027506-5912
Background/Aims: Thyroid hormones are involved in wide range of glucose metabolism functions. Overt thyroid dysfunctions are related to altered glucose homeostasis. However, it is not conclusive as to whether subtle changes in thyroid hormones within normal ranges can induce alterations in glucose homeostasis. The aim of this study was to evaluate the association between thyroid hormone and glucose homeostasis parameters in subjects without overt thyroid dysfunction based on nationwide population data.

Methods: In the Sixth Korea National Health and Nutrition Examination Survey 2015 ( $\mathrm{n}=7,380$ ), data were collected from subjects with insulin and thyroid function measurements who were older than 19-years-old. After the exclusion of 5,837 subjects, a total of 1,543 patients were included in the analysis. Subjects were categorized into the quartiles of the free thyroxine (FT4). Fasting glucose, insulin, homeostatic model assessment of insulin resistance and hemoglobin Aic (HbArc) levels were considered to be glucose homeostasis parameters.

Results: Subjects with the highest FT4 quartile showed significantly lower fasting insulin and $\mathrm{HbAic} \mathrm{levels.} \mathrm{A} \mathrm{significant} \mathrm{inverse} \mathrm{correlation} \mathrm{FT}_{4}$ and $\mathrm{HbArc} \mathrm{levels}$ was observed $(\beta=-0.261, p=0.025)$. In the logistic regression analysis, the highest quartile of $\mathrm{FT}_{4}$ was demonstrated to lower the risk of HbAic to a greater degree than the median by approximately $40 \%$, after adjusting for confounders, compared to the lowest quartile $(p=0.028)$.

Conclusions: We demonstrated subjects with a lower $\mathrm{FT}_{4}$ quartile exhibited high risk of $\mathrm{HbArc}$ levels above the median value in a representative Korean population. Subjects with the lowest FT4 quartile should be cautiously managed in terms of altered glucose homeostasis.

Keywords: Thyroid hormones; Blood glucose; Insulin resistance; Glycated hemoglobin A

\section{INTRODUCTION}

Glucose homeostasis reflects a balance between glucose production and peripheral glucose utilization. It refers to the process of maintaining blood glucose at a steadystate level [1]. The maintenance of normal glucose homeostasis requires a complex and highly integrated interaction among the liver, muscles, adipocytes, pancreas, 
neurotransmitters, and kidneys [2]. Several parameters reflect the status of glucose homeostasis. Fasting plasma glucose and insulin, which is a potent regulator of glucose homeostasis [3], are basic reflectors of glucose homeostasis. The homeostatic model assessment (HOMA) is a method for assessing $\beta$-cell function and insulin resistance based on fasting glucose, insulin, or C-peptide concentrations. The HOMA of insulin resistance (HOMA-IR) yields estimates of insulin sensitivity from fasting plasma glucose and insulin concentrations and is commonly used to evaluate insulin resistance and metabolic status [4]. Hemoglobin A1c (HbA1c) is well recognized and widely used for assessing the glycaemic control status [5]. It represents a 2 to 3 month mean of serum glucose concentrations and is a useful screening tool for type 2 diabetes [6]. HbArc is also a reliable marker for insulin resistance in normal, glucose tolerant adults [7].

Thyroid hormones serve an important role in regulating glucose metabolism. The liver [8-10], adipose tissue [8], skeletal muscle [11], and pancreas [12] are under the influence of thyroid hormone action. Many studies have elucidated the relationship between thyroid hormones and glucose homeostasis [10,13-15]. It is generally accepted that thyroid hormones have significant effects on glucose homeostasis and insulin resistance [9]. An alteration in glucose homeostasis is associated with overt thyroid dysfunction [16]. However, data on how glucose homeostasis changes in response to subtle thyroid hormone alterations are not yet consistent. Several studies have assessed the association between thyroid dysfunction and glucose homeostasis, but the data are conflicting $[14,15,17]$. Recently, Kim et al. [18] reported that $\mathrm{HbA1c}$ levels were high in non-diabetic patients with overt hypothyroidism, but only 45 patients were analysed. Thus, we investigated whether changes in thyroid hormones within normal ranges could affect glucose homeostasis parameters based on data from the latest nationally representative epidemiological survey (the Sixth Korea National Health and Nutrition Examination Survey [KNHANES VI]).

\section{METHODS}

\section{Study population}

The KNHANES VI was performed by the Korea Centers for Disease Control and Prevention (CDC) and comprised a health interview survey, a health examination survey, and a nutrition survey by using a stratified, multistage, probability sampling design. Informed written consent for participation was obtained from all of the study subjects. In addition, the study was approved by the Catholic University of Korea, Catholic Medical Center, Seoul St. Mary's Hospital Institutional Review Board (KC2OZISIo409). Of the 7,380 Korean participants, 1,435 individuals aged $<19$ years were excluded. Subjects who were pregnant $(n=6)$, who had a history of treatment for either thyroid disease $(n=36)$ or diabetes $(n=102)$, and for whom insufficient free thyroxine (FT4) data were available or FT4 was not within the normal range $(\mathrm{n}=3,992)$ were also excluded. Additionally, subjects were excluded if they did not maintain a fasting state of more than 8 hours before blood sampling $(n=46)$. Finally, 220 subjects were excluded who did not complete all of the required tests that were presented by the CDC. Ultimately, 1,543 participants were eligible for this study.

\section{Measurements}

All of the measurements and questionnaires were collected by specially trained investigators. Detailed anthropometric measurements were performed according to previous studies [19-21]. Height and body weight were measured as part of the health examination for each subject. Body mass index (BMI) was calculated from the measured height and weight values. The BMI values of subjects were categorized as underweight (< $\left.18.5 \mathrm{~kg} / \mathrm{m}^{2}\right)$, normal weight $\left(\geq 18.5\right.$ and $\left.<23 \mathrm{~kg} / \mathrm{m}^{2}\right)$, overweight $\left(\geq 23\right.$ and $\left.<25 \mathrm{~kg} / \mathrm{m}^{2}\right)$ or obese $\left(\geq 25 \mathrm{~kg} / \mathrm{m}^{2}\right)$. Serum creatinine, thyrotropin (TSH), FT4, anti-thyroid peroxidase antibody (TPO Ab), glucose, HbAic, and insulin levels were measured from sampled blood that was collected after 8 hours of overnight fasting. TSH levels were measured by using an E-TSH kit (Roche Diagnostics, Basel, Switzerland), for which the reference range was 0.35 to $5.50 \mu \mathrm{IU} / \mathrm{mL}$. FT4 levels were measured by using an E-Free $\mathrm{T}_{4}$ kit (Roche Diagnostics, Basel, Switzerland) for which the reference range was 0.89 to $1.76 \mathrm{ng} / \mathrm{mL}$. TPOAb levels were measured by using an E-Anti-TPO kit (Roche Diagnostics, Basel, Switzerland); the normal range for TPOAb in humans is $<34.0 \mathrm{IU} / \mathrm{mL}$. Serum creatinine levels were measured by using a Hitachi Automatic Analyzer 7600-210 (Hitachi, 
Tokyo, Japan), and the iodine intake status was evaluated by using the urine iodine creatinine ratio (UICR) determined using inductively coupled plasma mass spec trometry (PerkinElmer; Waltham MA, USA). Insulin levels were measured by using a gamma-counter (1470 WIZARD gamma-counter, PerkinElmer, Turku, Finland) with an immunoradiometric assay (INS-IRMA, Biosource, Nivelles, Belgium). Fasting plasma glucose levels were measured by using a Hitachi Automatic Analyser 7600. HbA1c levels were measured by using high-performance liquid chromatography (HLC723G7; Tosoh, Tokyo, Japan). The smoking statuses of subjects were classified as either non-smokers or current smokers. Physical activity was categorized into two groups: the regular physical activity group (exercised for $\geq 20 \mathrm{~min} / \mathrm{session}, \geq 5$ sessions/week; moderate exercise for $\geq 30 \mathrm{~min} / \mathrm{session} \geq 5$ sessions/week; or walking for $\geq 30 \mathrm{~min} / \mathrm{session}, \geq 5$ sessions/week) or the non-regular physical activity group. We calculated the HOMA-IR as (fasting serum insulin $[\mu \mathrm{IU} / \mathrm{mL}] \times$ fasting plasma glucose $[\mathrm{mmol} / \mathrm{L}] / 22.5)$ [22].

\section{Statistical analysis}

Statistical analyses were performed by using SAS version 9.3 (SAS Institute, Cary, NC, USA). A p values < 0.05 were considered to be statistically significant. Continuous variables are expressed as numbers and percentages or as means \pm standard deviations and compared by $t$ tests. Discrete variables are presented as number (\%) and compared by Rao-Scott chi-squared tests. Multivariable adjusted logistic regression analysis was conducted to determine odds ratios (ORs) and 95\% confidence intervals (CIs). In a logistic regression analysis, Model 1 was the age and sex adjusted model, whereas Model 2 was the model that was adjusted by age, sex, BMI, smoking status, physical activity, anti-TPO Ab levels, TSH levels, and urine iodine levels. Because of the complex sampling design, a sampling weight method was used to assign the participants as being representative of the Korean population for the analysis of the data. The detailed characteristics of the statistical analysis of the KNHANES have been previously reported [19-21].

\section{RESULTS}

\section{Baseline characteristics according to the $\mathrm{FT}_{4}$ quar- tiles}

The baseline characteristics of the 1,543 participants were analysed, as were age, sex, BMI, smoking status, physical activity, income, TPOAb levels, and UICR quartiles according to FT4 quartile (Table 1). With lower FT4 quartiles, higher ages and BMIs were observed ( $p$ for the trend $<0.001$ and $p$ for the trend $=0.027$, respectively). The proportion of males was observed to be higher in the highest FT4 quartiles. Subjects with the lowest FT4 quartiles exhibited higher TPOAb positivity ( $\geq 34 \mathrm{IU} /$ $\mathrm{mL}$ ) than other subjects. With lower FT4 quartiles, it was observed that more subjects belonged to the higher UICR quartiles $(p<0.001)$. No differences in smoking status or physical activity were observed by FT4 quartile.

\section{The association of $\mathrm{FT}_{4}$ with variables related to glu- cose homeostasis}

In the study population, the median values for fasting glucose, fasting insulin, HOMA-IR, and HbArc levels were $92.88 \mathrm{mg} / \mathrm{dL}, 6.27 \mu \mathrm{IU} / \mathrm{mL}, 1.47$, and 5.39\%, respectively (Supplementary Table 1). As shown in Table 2, fasting insulin levels were significantly decreased with increasing FT4 quartiles. HbArc levels were also significantly lowered with increasing FT4 quartiles. Subjects with $\mathrm{HbArc}$ levels less than the median value became more prevalent as the $\mathrm{FT}_{4}$ quartile increased (Table 2). In addition, it was observed that the risks of exceeding the median value of HbAlc (5.39\%) significantly decreased as the $\mathrm{FT}_{4}$ quartile increased (Table 3). In a regression analysis, only the $\mathrm{HbA1c}$ levels exhibited a significant inverse correlation with $\mathrm{FT}_{4}(\beta=-0.261, p$ $=0.025$ ) (Supplementary Table 2 ). The OR (95\% CI) for HbArc levels above the median value were 0.75 ( 0.50 to 1.12) in Q2, 0.69 (0.46 to 1.03) in Q3, and 0.61 (0.40 to 0.95) in $\mathrm{Q}_{4}$ ( $p$ for the trend < 0.001 ). However, in the analysis of fasting glucose, fasting insulin, and HOMA-IR levels, no significant risk increases according to $\mathrm{FT}_{4}$ quartile were observed.

\section{DISCUSSION}

In this population-based study, we observed a signifi- 
Table 1. Baseline characteristics of study subjects

\begin{tabular}{|c|c|c|c|c|c|c|}
\hline \multirow{2}{*}{ Characteristic } & \multicolumn{4}{|c|}{$\mathrm{FT}_{4}$ quartiles ${ }^{\mathrm{a}}$} & \multirow{2}{*}{$p$ value } & \multirow{2}{*}{$\begin{array}{l}p \text { for } \\
\text { trend }\end{array}$} \\
\hline & $Q_{1}(\mathrm{n}=351)$ & $Q_{2}(n=411)$ & $Q_{3}(\mathrm{n}=377)$ & $Q_{4}(n=404)$ & & \\
\hline Age, yr & $49.43 \pm 0.67$ & $45 \cdot 36 \pm 0.80$ & $43.79 \pm 0.84$ & $39.98 \pm 0.84$ & $<0.001$ & $<0.001$ \\
\hline Female sex & $220(61.4)$ & $224(53.0)$ & $204(54.0)$ & $119(28.9)$ & $<0.001$ & \\
\hline $\mathrm{BMI}, \mathrm{kg} / \mathrm{m}^{2}$ & $24.24 \pm 0.22$ & $24.23 \pm 0.20$ & $23.68 \pm 0.21$ & $23.67 \pm 0.21$ & 0.117 & 0.027 \\
\hline $\mathrm{FT}_{4}, \mathrm{ng} / \mathrm{mL}$ & $1.04 \pm 0.003$ & $1.18 \pm 0.001$ & $1.29 \pm 0.001$ & $1.46 \pm 0.006$ & $<0.001$ & $<0.001$ \\
\hline $\mathrm{TSH}, \mu \mathrm{IU} / \mathrm{mL}$ & $2.98 \pm 0.11$ & $2.57 \pm 0.08$ & $2.43 \pm 0.08$ & $2.36 \pm 0.08$ & $<0.001$ & $<0.001$ \\
\hline Fasting glucose, mg/dL & $96.84 \pm 0.91$ & $96.11 \pm 0.78$ & $94.39 \pm 0.83$ & $96.78 \pm 1.13$ & 0.205 & 0.716 \\
\hline Fasting insulin, uIU/mL & $8.09 \pm 0.41$ & $8.54 \pm 0.47$ & $8.02 \pm 0.45$ & $7.30 \pm 0.24$ & 0.049 & 0.048 \\
\hline HOMA-IR, mmol/L & $1.98 \pm 0.10$ & $2.09 \pm 0.12$ & $1.92 \pm 0.12$ & $1.80 \pm 0.08$ & 0.157 & 0.068 \\
\hline $\mathrm{HbAlc}, \%$ & $5.59 \pm 0.03$ & $5.50 \pm 0.02$ & $5.48 \pm 0.03$ & $5.46 \pm 0.04$ & 0.021 & 0.004 \\
\hline Smoking & & & & & 0.138 & \\
\hline No & $295(82.6)$ & $324(79.7)$ & $299(79 \cdot 3)$ & $299(74.7)$ & & \\
\hline Yes & $56(17 \cdot 4)$ & $87(20.3)$ & $78(20.7)$ & $105(25 \cdot 3)$ & & \\
\hline Physical activity & & & & & 0.094 & \\
\hline No & $174(47 \cdot 4)$ & $216(53.8)$ & $176(44.4)$ & $176(44.2)$ & & \\
\hline Yes & $177(52.6)$ & $195(46.2)$ & $201(55 \cdot 6)$ & $228(55.8)$ & & \\
\hline Anti-TPO Ab & $45.83 \pm 14.53$ & $34.97 \pm 9.74$ & $20.38 \pm 3.22$ & $20.45 \pm 5.95$ & 0.215 & 0.067 \\
\hline$<34 \mathrm{IU} / \mathrm{mL}$ & $313(88.9)$ & $383(94.0)$ & $348(93.0)$ & $385(95 \cdot 9)$ & 0.003 & \\
\hline$\geq 34 \mathrm{IU} / \mathrm{mL}$ & $38(11.1)$ & $28(6.0)$ & $29(7.0)$ & $19(4 \cdot 1)$ & & \\
\hline $\mathrm{UICR}^{\mathrm{a}}$ & & & & & $<0.001$ & \\
\hline$Q_{1}$ & $72(19.1)$ & $89(20.6)$ & $98(23.7)$ & $143(35 \cdot 7)$ & & \\
\hline $\mathrm{Q}_{2}$ & $73(18.5)$ & $99(23.7)$ & $106(29.4)$ & $113(27.9)$ & & \\
\hline$Q_{3}$ & $100(31.5)$ & $104(26.3)$ & $90(24.0)$ & $80(18.9)$ & & \\
\hline $\mathrm{Q}_{4}$ & $106(30.9)$ & $119(29.5)$ & $83(22.8)$ & $68(17.5)$ & & \\
\hline
\end{tabular}

Values are presented as mean \pm SD or number (\%). Statistics were carried out using Rao-Scott chi-square test and $t$ test.

FT4, free thyroxine; BMI, body mass index; TSH, thyrotropin; HOMA-IR, homeostasis model assessment of insulin resistance; HbAlc, hemoglobin A1c; TPO Ab, anti-thyroid peroxidase antibody; UICR, urine iodine creatinine ratio (iodine intake status was evaluated by urine iodine creatinine ratio).

${ }^{\mathrm{a}} \mathrm{Q} 1: \leq 1.125 \mathrm{ng} / \mathrm{mL} ; \mathrm{Q} 2:>\mathrm{Q} 1$ and $\leq 1.232 \mathrm{ng} / \mathrm{mL} ; \mathrm{Q} 3:>\mathrm{Q} 2$ and $\leq 1.344 \mathrm{ng} / \mathrm{mL} ; \mathrm{Q}_{4}:>$ Q3.

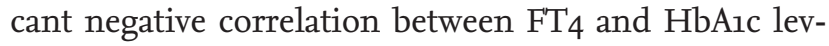
els. However, no significant associations of $\mathrm{FT}_{4}$ with other glucose homeostasis parameters, such as fasting glucose, insulin, and HOMA-IR levels, were observed. As the study aimed to evaluate the association of thyroid hormone and glucose metabolism, subjects with diabetes, who may have multiple factors influencing glucose homeostasis, were excluded. Additionally, subjects with overt thyroid dysfunctions, which could lead to pathologic alterations in metabolism were excluded. Thus, relatively healthy subjects were included in the study. Our results may demonstrate the summation of the complex effects of thyroid hormone on glucose homeostasis, which were revealed at the molecular level in healthy subjects.

Thyroid hormones are important determinants of glucose and lipid metabolism [13,23]. Thyroid hormones act on glucose homeostasis in various peripheral organs particularly the pancreas, muscle, adipose tissue, and liver [24], and thyroid hormones also exert central effects [25]. In particular, the roles of thyroid hormones in peripheral tissues have been extensively studied at the molecular level. For example, thyroid hormones regulate several key molecules in gluconeogenesis, such as phosphoe- 
Table 2. The relevance of FT4 quartiles to parameters related to glucose homeostasis

\begin{tabular}{|c|c|c|c|c|c|c|}
\hline \multirow{2}{*}{ Variable } & \multicolumn{4}{|c|}{ FT4 quartiles $^{\mathrm{a}}$} & \multirow{2}{*}{$p$ value } & \multirow{2}{*}{$\begin{array}{l}p \text { for } \\
\text { trend }\end{array}$} \\
\hline & $Q_{1}(\mathrm{n}=351)$ & $Q_{2}(n=411)$ & Q3 $(n=377)$ & $Q_{4}(n=404)$ & & \\
\hline Fasting glucose, $\mathrm{mg} / \mathrm{dL}$ & $96.84 \pm 0.91$ & $96.11 \pm 0.78$ & $94.39 \pm 0.83$ & $96.78 \pm 1.13$ & 0.205 & 0.716 \\
\hline$<$ Median $^{\mathrm{b}}$ & $153(42.9)$ & $192(45.1)$ & $190(50.5)$ & $200(46.9)$ & 0.354 & \\
\hline$\geq$ Median & $198(57.1)$ & $219(54 \cdot 9)$ & $187(49 \cdot 5)$ & $204(53.1)$ & & \\
\hline Fasting insulin, uIU/mL & $8.09 \pm 0.41$ & $8.54 \pm 0.47$ & $8.02 \pm 0.45$ & $7 \cdot 30 \pm 0.24$ & 0.049 & 0.048 \\
\hline$<$ Median $^{\mathrm{b}}$ & $169(49.1)$ & $192(47.1)$ & $189(49.8)$ & $206(50.3)$ & 0.864 & \\
\hline$\geq$ Median & $182(50.9)$ & $219(52.9)$ & $188(50.2)$ & $198(49 \cdot 7)$ & & \\
\hline HOMA-IR, \% & $1.98 \pm 0.10$ & $2.09 \pm 0.12$ & $1.92 \pm 0.12$ & $1.80 \pm 0.08$ & 0.157 & 0.068 \\
\hline$<$ Median $^{\mathrm{b}}$ & $167(49 \cdot 3)$ & $198(48.0)$ & $192(50.8)$ & $214(51.8)$ & 0.790 & \\
\hline$\geq$ Median & $184(50.7)$ & $213(52.0)$ & $185(49.2)$ & $190(48.2)$ & & \\
\hline HbAıc, \% & $5.59 \pm 0.03$ & $5.50 \pm 0.02$ & $5.48 \pm 0.03$ & $5.46 \pm 0.04$ & 0.021 & 0.004 \\
\hline$<$ Median $^{\mathrm{b}}$ & $110(29.0)$ & $163(38.0)$ & $161(42.5)$ & $194(48.3)$ & $<0.001$ & \\
\hline$\geq$ Median & $241(71.0)$ & $248(62.0)$ & $216(57.5)$ & $210(51.7)$ & & \\
\hline
\end{tabular}

Values are presented as mean \pm SD or number (\%). Statistics were carried out using Rao-Scott chi-square test and $t$ test.

$\mathrm{FT}_{4}$, free thyroxine; HOMA-IR, homeostasis model assessment of insulin resistance; HbA1c, hemoglobin A1c.

${ }^{\mathrm{a}} \mathrm{Q} 1: \leq 1.125 \mathrm{ng} / \mathrm{mL} ; \mathrm{Q} 2:>\mathrm{Q} 1$ and $\leq 1.232 \mathrm{ng} / \mathrm{mL} ; \mathrm{Q} 3:>\mathrm{Q} 2$ and $\leq 1.344 \mathrm{ng} / \mathrm{mL} ; \mathrm{Q} 4:>\mathrm{Q} 3$.

${ }^{\mathrm{b}}$ Median values for fasting glucose, fasting insulin, HOMA-IR, and HbAic were $92.88 \mathrm{mg} / \mathrm{dL}, 6.27 \mathrm{uIU} / \mathrm{mL}, 1.47$, and 5.39\%, respectively.

nolpyruvate carboxykinase [26] and glucose-6-phosphatase [27]. Alanine transport and its conversion to glucose in the liver were observed to be increased by thyroid hormones [28]. These hormones also contribute to hepatic insulin resistance, mainly via carbohydrate-response element-binding protein (ChREBP) [29]. Conversely, it also exerts effects on glucose consumption. $\mathrm{T}_{3}$ was observed to increase the glycolytic capacity via the regulation of the expression levels of several proteins, such as glucose transporter type 4 (GLUT-4) [30] and nicotinamide adenine dinucleotide phosphate (NADP)-dependent malic enzyme [31] in skeletal muscles. As physiological levels of thyroid hormone have been observed to exert protective effects on pancreas islets [32], thyroid hormones may favourable roles, in terms of lowering glucose levels. Alterations in glucose homeostasis in hyper- and hypothyroidism have been well summarized in a previous review article [16]. As suggested in many molecular studies, it has been definitively proven that thyroid hormones are associated with glucose homeostasis. However, as thyroid hormones serve important roles in both glucose production and consumption, it is difficult to expect whether high or low normal ranges of thyroid hormones are associated, or not associated, with favour- able glucose homeostasis.

Overt thyroid dysfunction is associated with atherosclerotic cardiovascular disease, and it has been extensively reviewed [33-35]. In hyperthyroidism, impaired glucose tolerance may be the result of hepatic insulin resistance, whereas hypothyroidism may be the result of insulin resistance of peripheral tissues [9]. Hyperthyroidism is one of several reversible causes of hyperglycaemia and is recognized to be associated with increased gluconeogenesis, increased rates of glucose absorption, and a decreased insulin half-life [35-37]. Maratou et al. [38] suggested that patients with overt hypothyroidism present with decreased levels of insulin-stimulated glucose transport in monocytes due to the disrupted translocation of the glucose transporter 4, which is responsible for glucose utilization. The development of insulin resistance in hypothyroidism is also associated with a decreased rate of blood flow in peripheral tissues, as Dimitriadis et al. [39] has previously described.

Subclinical thyroid dysfunction is associated with changes in glucose homeostasis [9]. HOMA-IR levels were significantly higher and a positive correlation between TSH and HOMA-IR levels was observed in a subject with subclinical hypothyroidism [40]. Al Sayed 


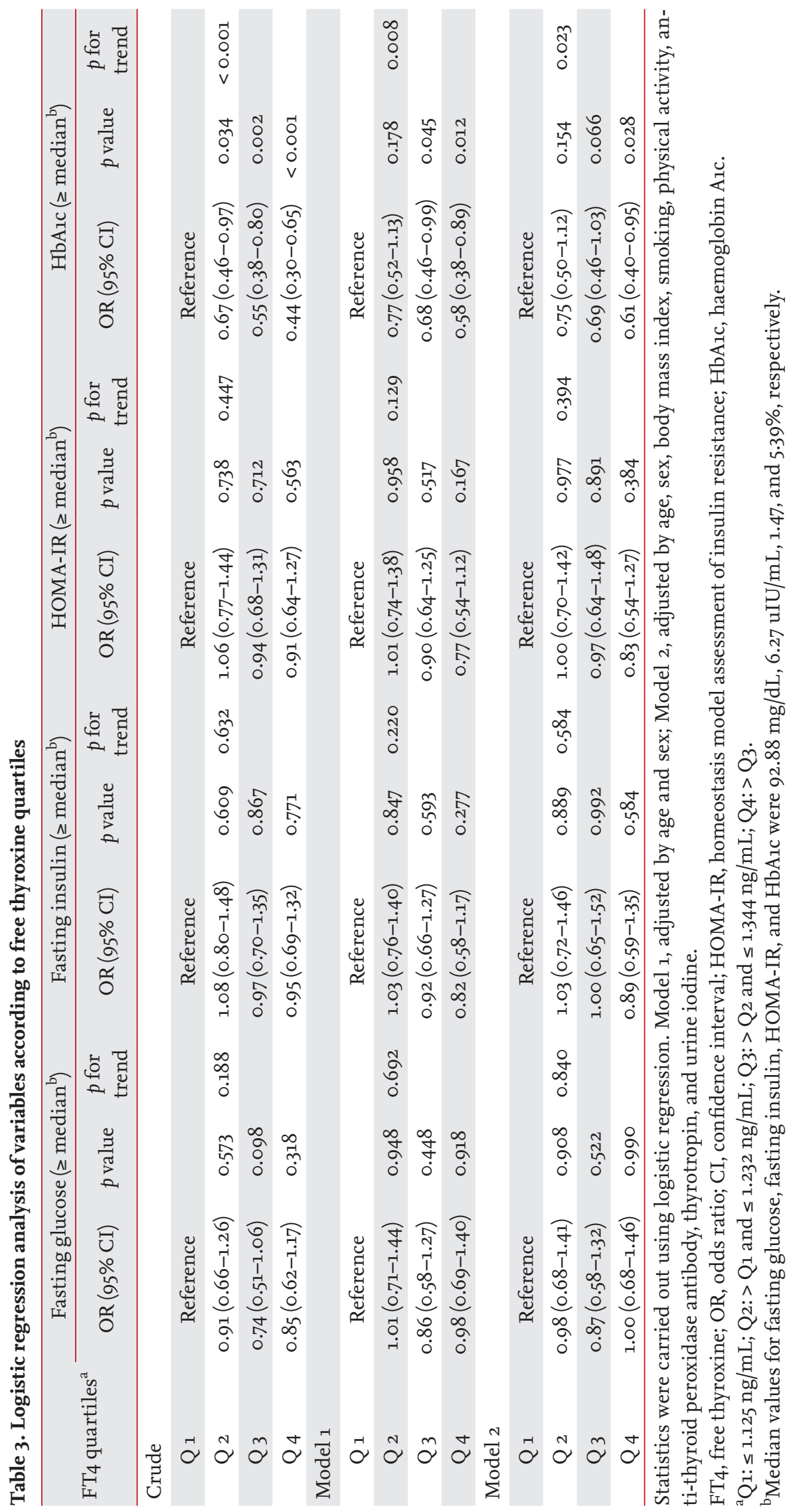


et al. [41] reported that increased insulin resistance was evident in subclinical hypothyroidism, but HOMA-IR levels were not significantly different from those of euthyroid subjects. Maratou et al. [42] suggested that this effect was attributed to the impaired translocation of GLUT-4 transporters in adipose tissue and muscle. Insulin resistance and impaired glucose tolerance are also observed in case of subclinical hyperthyroidism [38,43]. The sensitivity of glucose metabolism to insulin in a patient with subclinical hyperthyroidism was demonstrated to be lower than the sensitivity of glucose metabolism in a euthyroid subject [38]. Rezzonico et al. [43] reported that both exogenous and endogenous subclinical hyperthyroidism can lead to increased insulin resistance. The mechanism involved in this underlying pathophysiology is not yet known.

Whether subtle changes in FT4 levels within the euthyroid range alter glucose homeostasis has not yet been fully elucidated. Previously, Roos et al. [14] have demonstrated that fasting glucose and insulin levels were significantly related to lower FT4 levels in the analysis of 2,703 euthyroid subjects. In contrast to our study, Roos et al. [14] reported that HOMA-IR levels were correlated with low FT4 levels. This contrasting result may be explained by the fact that age was not adjusted for in their analysis. Serum FT4 levels generally tend to decrease with age [44]; therefore, the correction for age is important. In the Iranian study by Mehran et al. [45], FT4 levels in the euthyroid range were negatively correlated with HOMA-IR levels even after adjusting for age; however, the baseline BMI values of subjects were higher than those in our study. It was assumed that insulin resistance was slightly higher in the baseline subjects. In the Turkish study by Tarcin et al. [46], HOMA-IR levels were not correlated with $\mathrm{FT}_{4}$ levels, which was consistent with our results. The results cannot be generalized because there may be differences between the studies, depending on ethnicities and areas of residency. In the Chinese study by Lin et al. [47], BMI values and triglyceride levels were negatively correlated with $\mathrm{FT}_{4}$ levels in euthyroid subjects; however, no analyses of HOMA-IR and HbAic levels were made. Kim et al. [48] analysed 44,196 Korean population individuals and reported that fasting glucose levels were positively correlated with FT4 levels. This is different from our results, which is possibly due to the different exclusion criteria that were used between the two studies. In the present study, we excluded subjects with known case of diabetes mellitus $(n=102)$. Moreover, there was no analysis related to insulin resistance in the study by Kim et al. [48].

$\mathrm{HbA1c}$ levels have been widely used as an indicator of insulin resistance and for monitoring the degree of glucose control. They are also used as a surrogate marker of metabolic syndrome [49,50]. As with other indicators reflecting metabolic status, changes in HbArc levels have also been reported to be associated with overt thyroid dysfunction. Overt hypothyroidism was associated with higher HbA1c levels in non-diabetic patients, but only 45 subjects were analysed [18]. Christy et al. [51] found that HbA1c levels to be higher in patients with hypothyroidism, but this study included patients with anaemia. Other population-based studies have demonstrated the association between dysglycaemia and $\mathrm{FT}_{4}$ levels, but not with HbA1c levels [44,52]. Our study is the first community-based study that investigated the association of HbA1c levels with FT4 levels in euthyroid healthy subjects. As HbArc levels reflect the current glucose metabolism status regardless of different underlying mechanisms of disruptions in glucose homeostasis, it is a good clinical surrogate marker to initiate interventions for glucose control. Previous studies have demonstrated that low FT4 levels are associated with several metabolic components in the euthyroid state. In addition, our study confirms that low FT4 levels are associated with higher HbAic levels. In this regard, it is thought that a preliminary prediction of glucose metabolism is possible by confirming HbAic levels when lower FT4 levels and metabolic syndrome are accompanied in euthyroid subjects.

A limitation of this study was its cross-sectional design, which indicates that causality cannot be proven. The use of medications, the detailed histories of treatments, and the presence of medical illnesses, including thyroid disease or other illnesses were self-reported. However, the KNHANES is a confidence study, and this study is credible because specially trained investigators participated in the interviews. Another limitation was related to the interpretation of $\mathrm{HbArc}$ levels. HbArc levels may be measured at either falsely high or falsely low degree when the erythrocyte life span is changing. HbAic levels would be more accurately interpreted if the erythrocyte span was reflected. However, when considering 
the domestic overall prevalence of haematologic malignancies [53], the effect of erythrocyte condition is not expected to be significant in this healthy study population. In conclusion, we demonstrated subjects with a lower FT4 quartile exhibited high risk of HbA1c levels above the median value in a representative Korean population. In contrast, each parameter that is known to be involved in glucose homeostasis, such as fasting glucose, insulin, or HOMA-IR levels was not significantly related to FT4 quartile. Together with previous findings, lower FT4 levels in the euthyroid range may be associated with altered or adverse glucose homeostasis. These findings are also related to increased cardiovascular risk in overt hypothyroidism or subclinical hypothyroidism. Future large cohort studies are needed, with sufficient follow-up periods, to determine the effects of thyroid hormones on the development of unfavourable clinical outcomes, such as cardiovascular or metabolic diseases.

\section{KEY MESSAGE}

1. Subjects with a lower free thyroxine $\left(\mathrm{FT}_{4}\right)$ quartile exhibited high risk of hemoglobin Aic levels above the median value in a representative Korean population.

2. Together with previous findings, lower $\mathrm{FT}_{4}$ levels in the euthyroid range may be associated with altered or adverse glucose homeostasis.

\section{Conflict of interest}

No potential conflict of interest relevant to this article was reported.

\section{Acknowledgments}

This work was supported by National Research Foundation Basic Research in Science \& Engineering Individual Research Program (NRF-2017R1D1A1B03030159). Also, the authors wish to acknowledge the financial support of the Catholic Medical Center Research Foundation made in the program year of 2018. The consultation for statistical analysis was supported by a grant from the Korea Health Technology R\&D Project through the Korea Health Industry Development Institute, funded by the Ministry of Health and Welfare, Republic of Korea (Grant number: HI14C1062).

\section{REFERENCES}

1. DeFronzo RA. Lilly lecture 1987. The triumvirate: beta-cell, muscle, liver. A collusion responsible for NIDDM. Diabetes 1988;37:667-687.

2. Defronzo RA. Banting Lecture. From the triumvirate to the ominous octet: a new paradigm for the treatment of type 2 diabetes mellitus. Diabetes 2009;58:773-795.

3. Plum L, Belgardt BF, Bruning JC. Central insulin action in energy and glucose homeostasis. J Clin Invest 2006;116:1761-1766.

4. Kapadia KB, Bhatt PA, Shah JS. Association between altered thyroid state and insulin resistance. J Pharmacol Pharmacother 2012;3:156-160.

5. Florkowski C. HbAıc as a diagnostic test for diabetes mellitus: reviewing the evidence. Clin Biochem Rev 2013;34:75-83.

6. Kahn BB. Type 2 diabetes: when insulin secretion fails to compensate for insulin resistance. Cell 1998;92:593-596.

7. Borai A, Livingstone C, Abdelaal F, Bawazeer A, Keti V, Ferns G. The relationship between glycosylated haemoglobin $(\mathrm{HbAlc})$ and measures of insulin resistance across a range of glucose tolerance. Scand J Clin Lab Invest 2011;71:168-172.

8. Sinha RA, Singh BK, Yen PM. Thyroid hormone regulation of hepatic lipid and carbohydrate metabolism. Trends Endocrinol Metab 2014;25:538-545.

9. Gierach M, Gierach J, Junik R. Insulin resistance and thyroid disorders. Endokrynol Pol 2014;65:70-76.

10. Mullur R, Liu YY, Brent GA. Thyroid hormone regulation of metabolism. Physiol Rev 2014;94:355-382.

11. Salvatore D, Simonides WS, Dentice M, Zavacki AM, Larsen PR. Thyroid hormones and skeletal muscle: new insights and potential implications. Nat Rev Endocrinol 2014;10:206-214.

12. Chen C, Xie Z, Shen Y, Xia SF. The roles of thyroid and thyroid hormone in pancreas: physiology and pathology. Int J Endocrinol 2018;2018:2861034.

13. Dimitriadis GD, Raptis SA. Thyroid hormone excess and glucose intolerance. Exp Clin Endocrinol Diabetes 2001;109 Suppl 2:S225-S239.

14. Roos A, Bakker SJ, Links TP, Gans RO, Wolffenbuttel BH. Thyroid function is associated with components of the metabolic syndrome in euthyroid subjects. J Clin Endocrinol Metab 2007;92:491-496.

15. Kommareddy S, Lee SY, Braverman LE, Pearce EN. Thy- 
roid function and metabolic syndrome: a cross-sectional study in obese and overweight patients. Endocr Pract 2015;21:1204-1210.

16. Martinez B, Ortiz RM. Thyroid hormone regulation and insulin resistance: insights from animals naturally adapted to fasting. Physiology (Bethesda) 2017;32:141-151.

17. Amati F, Dube JJ, Stefanovic-Racic M, Toledo FG, Goodpaster BH. Improvements in insulin sensitivity are blunted by subclinical hypothyroidism. Med Sci Sports Exerc 2009;41:265-269.

18. Kim MK, Kwon HS, Baek KH, et al. Effects of thyroid hormone on $\mathrm{AlC}$ and glycated albumin levels in nondiabetic subjects with overt hypothyroidism. Diabetes Care 2010;33:2546-2548.

19. Ha J, Jo K, Lim DJ, et al. Parathyroid hormone and vitamin $\mathrm{D}$ are associated with the risk of metabolic obesity in a middle-aged and older Korean population with preserved renal function: a cross-sectional study. PLoS One 2017;12:eo175132.

20. Ha J, Lee J, Jo K, et al. Sex differences in risk factors for subclinical hypothyroidism. Endocr Connect 2018;7:511522.

21. Kim J. Association between serum vitamin D, parathyroid hormone and metabolic syndrome in middle-aged and older Korean adults. Eur J Clin Nutr 2015;69:425-430.

22. Wallace TM, Levy JC, Matthews DR. Use and abuse of HOMA modeling. Diabetes Care 2004;27:1487-1495.

23. Duntas LH. Thyroid disease and lipids. Thyroid 2002;12:287293.

24. Potenza M, Via MA, Yanagisawa RT. Excess thyroid hormone and carbohydrate metabolism. Endocr Pract 2009;15:254-262.

25. Lopez M, Alvarez CV, Nogueiras R, Dieguez C. Energy balance regulation by thyroid hormones at central level. Trends Mol Med 2013;19:418-427.

26. Park EA, Song S, Vinson C, Roesler WJ. Role of CCAAT enhancer-binding protein beta in the thyroid hormone and cAMP induction of phosphoenolpyruvate carboxykinase gene transcription. J Biol Chem 1999;274:211-217.

27. Suh JH, Sieglaff DH, Zhang A, et al. SIRT1 is a direct coactivator of thyroid hormone receptor $\beta 1$ with gene-spe cific actions. PLoS One 2013;8:e70097.

28. Singh SP, Snyder AK. Effect of thyrotoxicosis on gluconeogenesis from alanine in the perfused rat liver. Endocrinology 1978;102:182-187.

29. Poupeau A, Postic C. Cross-regulation of hepatic glucose metabolism via ChREBP and nuclear receptors. Biochim Biophys Acta 2011;1812:995-1006.

30. Zorzano A, Palacin M, Guma A. Mechanisms regulating GLUT4 glucose transporter expression and glucose transport in skeletal muscle. Acta Physiol Scand 2005;183:43-58.

31. Desvergne B, Petty KJ, Nikodem VM. Functional characterization and receptor binding studies of the malic enzyme thyroid hormone response element. J Biol Chem 1991;266:1008-1013.

32. Verga Falzacappa C, Mangialardo C, Madaro L, et al. Thyroid hormone $\mathrm{T}_{3}$ counteracts STZ induced diabetes in mouse. PLoS One 2011;6:e19839.

33. Cappola AR, Ladenson PW. Hypothyroidism and atherosclerosis. J Clin Endocrinol Metab 2003;88:2438-2444.

34. Klein I, Ojamaa K. Thyroid hormone and the cardiovascular system. N Engl J Med 2001;344:501-509.

35. Kreines K, Jett M, Knowles HC Jr. Observations in hyperthyroidism of abnormal glucose tolerance and other traits related to diabetes mellitus. Diabetes 1965;14:740744 .

36. Feng X, Jiang Y, Meltzer P, Yen PM. Thyroid hormone regulation of hepatic genes in vivo detected by complementary DNA microarray. Mol Endocrinol 2000;14:947955.

37. Dimitriadis G, Baker B, Marsh H, et al. Effect of thyroid hormone excess on action, secretion, and metabolism of insulin in humans. Am J Physiol 1985;248(5 Pt 1):E593-E6o1.

38. Maratou E, Hadjidakis DJ, Peppa M, et al. Studies of insulin resistance in patients with clinical and subclinical hyperthyroidism. Eur J Endocrinol 2010;163:625-630.

39. Dimitriadis G, Mitrou P, Lambadiari V, et al. Insulin action in adipose tissue and muscle in hypothyroidism. J Clin Endocrinol Metab 2006;91:4930-4937.

40. Vyakaranam S, Vanaparthy S, Nori S, Palarapu S, Bhongir AV. Study of insulin resistance in subclinical hypothyroidism. Int J Health Sci Res 2014;4:147-153.

41. Al Sayed A, Al Ali N, Bo Abbas Y, Alfadhli E. Subclinical hypothyroidism is associated with early insulin resistance in Kuwaiti women. Endocr J 2006;53:653-657.

42. Maratou E, Hadjidakis DJ, Kollias A, et al. Studies of insulin resistance in patients with clinical and subclinical hypothyroidism. Eur J Endocrinol 2009;160:785-790.

43. Rezzonico J, Niepomniszcze H, Rezzonico M, Pusiol E, Alberto M, Brenta G. The association of insulin resistance with subclinical thyrotoxicosis. Thyroid 2011;21:945-949. 
44. Sawin CT, Chopra D, Azizi F, Mannix JE, Bacharach P. The aging thyroid. Increased prevalence of elevated serum thyrotropin levels in the elderly. JAMA 1979;242:247-250.

45. Mehran L, Amouzegar A, Tohidi M, Moayedi M, Azizi F. Serum free thyroxine concentration is associated with metabolic syndrome in euthyroid subjects. Thyroid 2014;24:1566-1574.

46. Tarcin O, Abanonu GB, Yazici D, Tarcin O. Association of metabolic syndrome parameters with $\mathrm{TT}_{3}$ and $\mathrm{FT}_{3} / \mathrm{FT}_{4}$ ratio in obese Turkish population. Metab Syndr Relat Disord 2012;10:137-142.

47. Lin SY, Wang YY, Liu PH, Lai WA, Sheu WH. Lower serum free thyroxine levels are associated with metabolic syndrome in a Chinese population. Metabolism 2005:54:15241528.

48. Kim BJ, Kim TY, Koh JM, et al. Relationship between serum free $\mathrm{T}_{4}\left(\mathrm{FT}_{4}\right)$ levels and metabolic syndrome (MS) and its components in healthy euthyroid subjects. Clin Endocrinol (Oxf) 2009;70:152-160.

49. Osei K, Rhinesmith S, Gaillard T, Schuster D. Is glycosylated hemoglobin Aic a surrogate for metabolic syndrome in nondiabetic, first-degree relatives of African-American patients with type 2 diabetes? J Clin Endocrinol Metab 2003;88:4596-4601.

50. O'Sullivan CJ, Hynes N, Mahendran B, et al. Haemoglobin $\mathrm{Alc}_{1 \mathrm{c}}(\mathrm{HbAlC})$ in non-diabetic and diabetic vascular patients. Is $\mathrm{HbAlC}$ an independent risk factor and predictor of adverse outcome? Eur J Vasc Endovasc Surg 2006;32:188-197.

51. Christy AL, Manjrekar P, Babu RP, Rukmini MS, Hegde A. Elevation of $\mathrm{HbAlC}$ in non-diabetic hypothyroid individuals: is anaemia the connecting link? A preliminary study. J Clin Diagn Res 2013;7:2442-2444.

52. Mehran L, Amouzegar A, Rahimabad PK, Tohidi M, Tahmasebinejad Z, Azizi F. Thyroid function and metabolic syndrome: a population-based thyroid study. Horm Metab Res 2017;49:192-200.

53. Park HJ, Park EH, Jung KW, et al. Statistics of hematologic malignancies in Korea: incidence, prevalence and survival rates from 1999 to 2008. Korean J Hematol 2012;47:28-38. 
Supplementary Table 1. The quartile value of each variables

\begin{tabular}{lccc}
\hline Variable & Q1 & Q2 (median) & Q3 \\
\hline TSH, uIU/mL & 1.501 & 2.251 & 3.248 \\
FT4, ng/dL & 1.125 & 1.232 & 1.344 \\
Urine iodine creatinine ratio & 99.121 & 170.586 & 399.300 \\
Fasting glucose, $\mathrm{mg} / \mathrm{dL}$ & & 92.883 & 6.267 \\
Fasting insulin, uIU/mL & & 1.466 & 5.385 \\
HOMA-IR & & & \\
HbAic, \% & & & \\
\hline
\end{tabular}

TSH, thyrotropin; FT4, free thyroxine; HOMA-IR, homeostasis model assessment of insulin resistance; HbAic, hemoglobin Aic. 
Ha J, et al. Thyroid function and metabolic status

Supplementary Table 2. The result of standardized beta coefficient for each variable related to free thyroxine

\begin{tabular}{lcc}
\hline Variable & $\beta$ Coefficient & $p$ value \\
\hline Fasting glucose & 0.329 & 0.921 \\
Fasting insulin & -1.627 & 0.076 \\
HOMA-IR & -0.400 & 0.098 \\
HbAic & -0.261 & 0.025 \\
Age & -21.269 & $<0.001$ \\
Urine iodine & -407.778 & 0.349 \\
\hline
\end{tabular}

HOMA-IR, homeostasis model assessment of insulin resistance; HbArc, hemoglobin Arc. 